\title{
Retour sur « La Collecte des termites »
}

\section{Frédéric Joulian et Paulette Roulon-Doko}

\section{OpenEdition \\ Journals}

Édition électronique

URL : https://journals.openedition.org/tc/5041

DOI : $10.4000 /$ tc. 5041

ISSN : 1952-420X

Éditeur

Éditions de l'EHESS

\section{Édition imprimée}

Date de publication : 30 juin 2010

Pagination : 386-388

ISSN : 0248-6016

\section{Référence électronique}

Frédéric Joulian et Paulette Roulon-Doko, « Retour sur « La Collecte des termites » », Techniques \&

Culture [En ligne], 54-55 | 2010, mis en ligne le 30 juin 2013, consulté le 29 septembre 2022. URL http://journals.openedition.org/tc/5041 ; DOl : https://doi.org/10.4000/tc.5041 

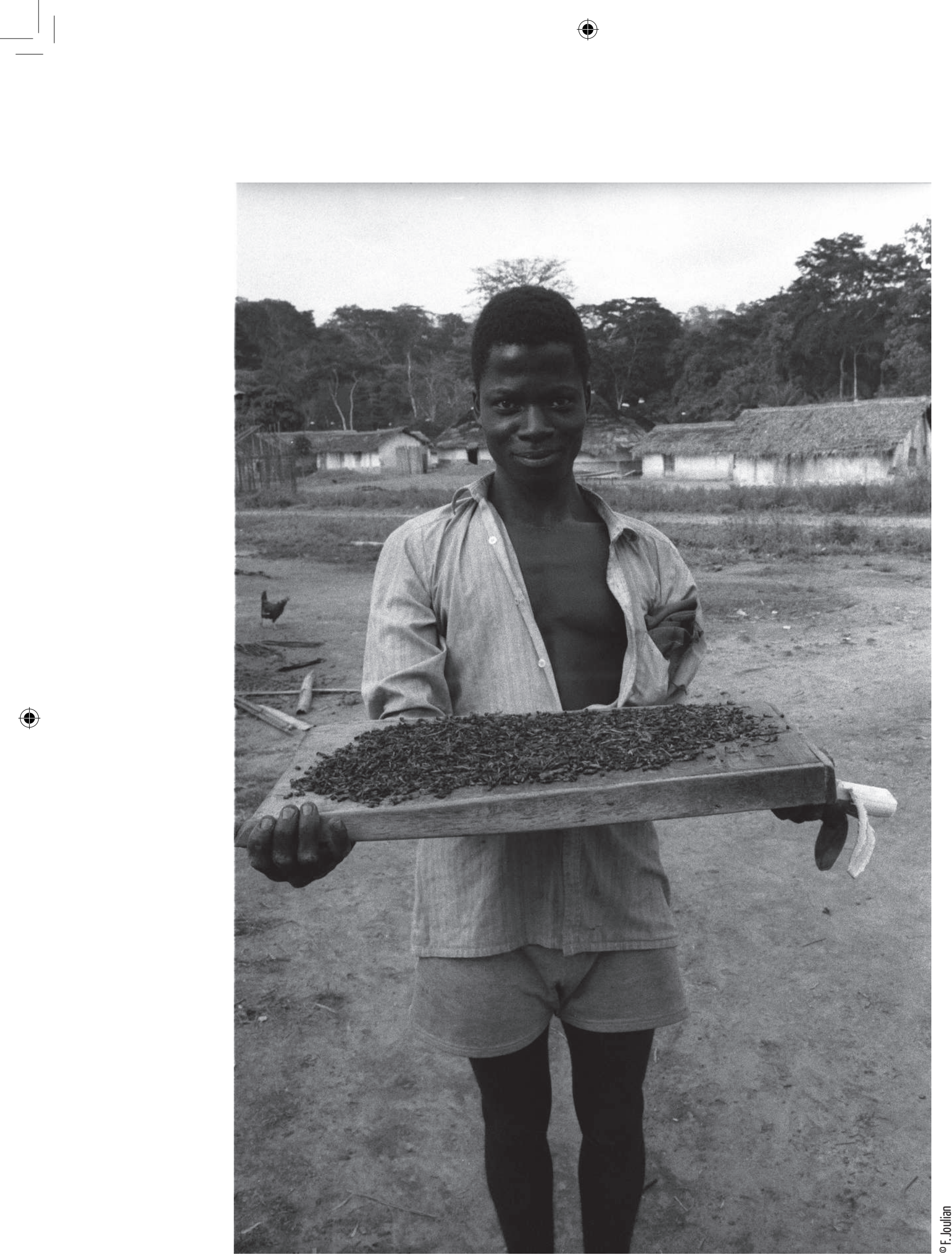

$\oplus$ 䇏 


\section{Retour sur}

\section{« La Collecte des termites »}

Ce texte, rédigé au début des années quatre-vingt-dix, se fondait sur une double expérience, celle de Paulette Roulon-Doko qui achevait à cette période une imposante monographie d'ethnolinguistique sur la culture matérielle des Gbaya de Centrafrique (thèse d'état soutenue en 1992) et la mienne, après un long terrain éthologique sur les chimpanzés de la Côte d'Ivoire et la soutenance d'une thèse sur « le problème de la culture » chez les chimpanzés et les premiers hominidés (1993), mais aussi et surtout, sur l'expérience d'un rendez-vous manqué entre éthologie et anthropologie que j'avais vécu lors du colloque « Man the Hunter » à Londres en 1986 (Ingold et al. 1988).

McGrew (1987) qui avait exposé à Londres et auquel nous répondions dans cet article utilisait le cadre d'analyse de la complexité technique forgé par Oswalt (1976) et comparait les outillages des chimpanzés de Tanzanie à ceux des chasseurs-cueilleurs tasmaniens et concluait dans une même métrique englobante que les chimpanzés étaient presque des hommes du point de vue de leur « technologie». Une telle proposition suscitait de vives réactions et les débats versèrent rapidement sur un plan idéologique. Ils allaient par la suite se rigidifier et ouvrir à une « primatologie culturelle» militante (McGrew 2003).

Une nouvelle « minorité » celle des « primates non-humains » (Joulian 2009) était née! Toutes les forces et faiblesses de ce type d'engagement appuyé d'un arsenal terminologique emprunté à une vieille anthropologie (culturaliste diffusionniste), quantitatif et métrique (celui de la biologie comportementale) s'alliaient étrangement aux discours post-modernes alors en expansion.

Mes perspectives comparatives d'alors étaient plus modestes: comparer des activités analogues chez deux espèces différentes, chimpanzés et hommes modernes dans le cas de l'article suivant, primates et hommes préhistoriques anciens (Australopithèques ou Homo), dans le cas d'autres travaux (1994, 1995), le but étant, par la comparaison étroite 
de leurs techniques, de développer une « étho-archéologie » (sur le modèle de l'ethnoarchéologie) en transférant des connaissances d'un corpus plus informé à un autre, plus lacunaire. Nous cherchions simplement à mieux comprendre et interpréter les activités motrices, économiques ou cognitives, voire fonctionnelles, des hommes et des primates; les dimensions sociales et historiques ne venant que plus tard.

Le gros des données éthologiques portait alors sur les conduites de subsistance. L'insectivorie des chimpanzés, propice à la fabrication et utilisation d'outils venait contredire la paléoanthropologie et la préhistoire qui fondaient encore et toujours l'hominisation intelligente sur l'outil et la carnivorie. L'enjeu évolutif était premier, mais également celui de la comparaison entre espèces qu'il fallait aborder empiriquement pour sortir des impasses de l'anthropomorphisme ou du zoomorphisme. Du côté de l'ethnologie, les travaux sur l'acquisition et la consommation des insectes étaient très rares et en France seule Paulette Roulon-Doko s'y était intéressée et avait décrit par le menu les activités de prédation d'insectes en plus de celles de chasse ou de cueillette (1980 à 2010).

Sur la base de nos deux corpus d'activités nous pouvions donc, en utilisant les instruments de l'anthropologie des techniques (mais également de l'ethnolinguistique) analyser finement une activité de subsistance avec ses outils, processus, savoir, savoirfaire et non comme cela se faisait du côté anglo-saxon, qualifier la culture matérielle d'un groupe culturel donné ou a fortiori d'une espèce ou d'un genre (Wynn, McGrew 1989). La question évolutive sous-jacente dès lors qu'on implique les animaux dans la comparaison était suffisamment complexe pour ne pas la prendre trivialement. Notons que sur cette interface homme/animal s'engageaient alors toutes sortes d'enjeux liés aux conditions de scientificité des sciences de la nature et des sciences de l'homme (de Cheveigné \& Joulian 2008).

Depuis la parution de cet article, les travaux ethnographiques portant sur l'activité de consommation d'insectes se sont peu développés (hormis ceux de Roulon-Doko) au profit, bien normal, d'études sur de nouvelles pratiques alimentaires (acculturées, enculturées, globalisées et mondialisées). À l'inverse, l'éthologie des chimpanzés, tant en captivité qu'en milieu naturel, s'est amplement étendue dans des cadres comparatifs ambitieux mais discutables tant sur des questions de variations traditionnelles des outils et comportements que des questions de transmission, de variabilité et de flexibilité comportementale (Nishida 1999; Whiten et al. 1999 ; Joulian 2000, 2005).

D’autres découvertes ont par ailleurs été réalisées par des préhistoriens expérimentalistes qui analysèrent des outils osseux des sites paléolithiques d'Afrique du Sud et conclurent à « la pêche aux termites » par les hominidés d'il y a 1,5 Ma. (Backwell, d'Errico, 2001; Joulian 2001).

Pour finir, rappelons que cet article sur les termites s'inscrivait dans un numéro double « Des cultures de bêtes aux outils qui pensent... via l'anthropologie » aux côtés d'autres recherches sur l'animal avec la question culturelle (Boesch), les capacités cognitives outillées des primates (Vauclair, Anderson) ou celle de la transmission (Thierry). Il se trouvait également associé à un deuxième volet, cybernétique, dans lequel la question de l'autonomie réelle ou fictive des machines jouait encore fortement. En mettant l'anthropomorphisme méthodologique au centre de son propos, Jean-Luc Jamard (1994) prenait la mesure de ces deux poussées synchrones, « animale » et « informatique ». Désormais, «bêtes » et «machines » vivent leurs propres vies et la place de l'homme, non pas dans la nature, mais « avec les natures, dans l'espace et le temps », prouve plus que jamais son actualité. 